\title{
THE MEDIATING ROLE OF KNOWLEDGE SHARING IN THE EFFECT OF TRANSACTIONAL LEADERSHIP AND TRANSFORMATIONAL LEADERSHIP ON THE ORGANIZATIONAL CREATIVITY
}

\author{
DOI: 10.17261/Pressacademia.2019.1068 \\ PAP- V.9-2019(15)-p.69-73
}

Mahmut Paksoy ${ }^{1}$, Tugce Kumral ${ }^{2}$, Pinar Sarp ${ }^{3}$

${ }^{1}$ istanbul Kultur University, School of Business, Istanbul, Turkey m.paksoy@iku.edu.tr, ORCID: 0000-0002-7055-5832

${ }^{2}$ istanbul Kultur University, School of Business, Istanbul, Turkey t.kumral@iku.edu.tr, ORCID: 0000-0003-4529-6231

3 istanbul Kultur University, School of Business, Istanbul, Turkey p.sarp@iku.edu.tr, ORCID: 0000-0003-3022-5182

To cite this document

Paksoy, M., Kumral, T., Sarp, P., (2019). The mediating role of knowledge sharing in the effect of transactional leadership and transformational leadership on the organizational creativity. PressAcademia Procedia (PAP), V.9, p.69-73 Permemant link to this document: $\mathrm{http} / / /$ doi.org/10.17261/Pressacademia.2019.1068 Copyright: Published by PressAcademia and limited licenced re-use rights only.

\begin{abstract}
Purpose- The main aim of this study is to determine the mediating role of information sharing in the effect of trancastional and transformational leadership on organizational creativity.

Methodology- In the research, quantitative research method was preferred and the data were collected via electronic surveys from livewares by convenience sampling method. As a result of the data collection process, 162 questionnaires were obtained.

Findings- After obtaining the data, SPSS 23.0 program was used for statistical analysis such as validity and reliability analysis, hierarchical regression analysis and t-test and Anova tests in the context of demographic variables.

Conclusion- It has been determined that transactional leadership and transformational leadership have a significant effect on knowledge sharing and organizational creativity. At the same time, it has been determined that information sharing has no mediating role in the effect of transactional leadership on organizational creativity and that information sharing has partial mediating role in the effect of transformational leadership on organizational creativity.
\end{abstract}

Keywords: Transactional leadership, transformational leadership, organizational creativity, knowledge sharing JEL Codes: M10, L02, M19.

\section{TRANSAKSIYONEL VE TRANSFORMASYONEL LIDERLIĞIN ÖRGÜTSEL YARATICILIĞA ETKISINDE BíLGi PAYLAŞIMININ ARACI ROLÜ}

\section{ÖZET}

Amaç- Bu araştırmanın amacı, transaksiyonel (işlemsel) ve transformasyonel (dönüştürücü) liderliğin örgütsel yaratıcılık üzerindeki etkisinde bilgi paylaşımının aracı rolünü tespit etmektir.

Yöntem- Araştırmada nicel araştırma yöntemi tercih edilmiş, veriler kolayda örnekleme yöntemi ile bilişim sektörü çalışanlarından elektronik ortamda anketler aracılığı ile toplanmıştır. Veri toplama süreci sonucunda 162 adet anket elde edilmiştir.

Bulgular- Veriler elde edildikten sonra SPSS 23.0 programından faydalanarak geçerlilik ve güvenilirlik analizleri, hiyerarşik regresyon analizi ve demografik değișkenler bağlamında t-testi ve Anova testleri gibi istatistiki analizlere tabi tutulmuştur.

Sonuç- Transaksiyonel liderliğin ve transformasyonel liderliğin bilgi paylaşımı ve örgütsel yaratıcılık üzerinde anlamlı bir etkisi olduğu sonucuna ulaşıımışıı. Aynı zamanda transaksiyonel liderliğin örgütsel yaratııılık üzerindeki etkisinde bilgi paylaşımının aracılık rolünün olmadığı ve transformasyonel liderliğin örgütsel yaratııılık üzerindeki etkisinde bilgi paylaşımının kısmi aracılık rolünün olduğu sonucuna ulaşılmıştır.

Anahtar Kelimeler: Transaksiyonel iderlik, transformasyonel liderlik, örgütsel yaratıcılık, bilgi paylaşımı.

JEL Kodları: M10, L02, M19 


\section{GíRiş}

Liderlik, yönetim alanında üzerinde çok durulan ve tam olarak açıklanamayan önemli bir kavramdır. Çünkü lider, örgütün hedeflerine ulaşabilmesi için hayatta kalmasını, gelişmesini sağlamada yaratıcı, başlatıcı rol üstlenen bireydir. Başka bir söylemle liderlik, izleyicileri yönetebilme ve ikna edebilme sanatıdır. Özellikle sosyal ve açık sistemlerde beraber çalışan bireyler tarafından oluşturulan ve karşı taraf için değer oluşturan ürün, hizmet olan örgütsel yaratıcılık, nitelik, nicelik, maliyet ve müşteri memnuniyeti bakımından önem teşkil etmektedir. Bu noktada liderlik kavramı çalışanları örgütsel yaratıcılığa sevk edebilmek adına motive edici bir güç olarak görülebilmektedir. Örgütsel yaratıcılığı artırabilmek için farklı disiplinlerle ilgili konferanslar düzenlenerek, bilgi paylaşımları yapılarak çalışanların daha etkin olması hususunda farkındalık oluşturulabilir.

\section{LITERATÜR INCELEMESI}

\subsection{Transaksiyonel Liderlik}

Transaksiyonel liderlik; izleyici ve liderlerin etkileşim içinde olduğu ve her iki tarafında motivasyon düzeyini yükselten bir liderlik biçimidir (Northhouse, 2004,170). Transaksiyonel liderlik davranışı, liderler ve izleyicileri arasındaki belirlenen hedeflere ve beklenen performansa ulaşmak için beklentileri belirlemek, sorumlulukları açığa kavuşturmak, anlaşmaları müzakere etmek, ödüller ve takdir sağlamak konularında temel oluşturmaktadır (Bass, 1985:64). Bu yaklaşıma göre; liderin, takipçilerden bazı beklentileri bulunmaktadır. Eğer bu beklentiler gerçekleşirse, lider takipçilerini ödüllendirmektedir (Trapero ve De Lozada, 2010:63). Transaksiyonel liderler, çalışanlarını takdir ve ödüller aracılığıyla yeni fikirler geliştirmeye teşvik edebilirler (Hussain vd., 2017:3). Aynı zamanda bu takdir ve ödüller, organizasyondaki bilgi paylaşımını da teşvik eder (Hussain vd., 2017:4).

\subsection{Transformasyonel Liderlik}

Transformasyonel liderlik ilk olarak 1973 yılında Dawston’un “isyan Liderliği (Rebel Leadership) adlı çalışmasında belirtilmiştir. Bass, transformasyonel ve transaksiyonel liderlik tiplerinin kavramsallaşmasında ve teorik çerçevenin oluşturulmasında geliştirmiş olduğu "Çoklu Liderlik Anketi (MLQ)" nin yer aldığı çalışmasını geliştirdiği yıllarda, transformasyonel lideri; “örgüt çalışanlarına cesaretle, korkusuzca radikal değişiklikler yapan, entelektüel uyarım sağlayan ve onlarda enerji uyandıran kişi” olarak tanımlamaktadır (Bass, 1990:21). Başka bir deyişle, transformasyonel liderlik çalışanlara vizyon kazandıran, bu vizyona katkıda bulunmaları için onlara ilave misyonlar veren ve örgütsel kültürde değişimler yaparak onlara şimdi yaptıklarından veya potansiyel olarak yapabileceklerini düşündüklerinden daha fazlasını yapabileceklerine inandıran liderlik tarzıdır (Kırılmaz ve Kırılmaz, 2010:120). Transformasyonel liderlik, günümüzde oldukça hızlı değişimlerin yer almasından dolayı; yenilikçi, yaratıcı ve esnek organizasyonel yapılar üretmede etkili bir liderlik yaklaşımıdır (Edizler ve Akbulut, 2011: 21). Bazı araştırmacılar dönüşümcü liderlerin, bilgiyle ilgili bir dizi değer, varsayım ve inanç geliştirerek çalışanların bilgi paylaşımı faaliyetlerine yönelik davranışlarını şekillendiren bilgili ve destekleyici bir kültür kurduklarını ileri sürmüşlerdir (Birasnav vd., 2011:108).

\section{3. Örgütsel Yaratıcılık}

Yaratıcılık fikir üretme sürecidir ve yeni sosyo-ekonomik standartlar oluşturabilecek, yeniliğe doruğa ulaşabilecek yeni bir unsurun ortaya çıkmasını gerektirir (Amabile, 1997). Yaratıcılık iki ayrı düzeyde incelenmektedir. Bu düzeylerden ilki bireysel, ikincisi ise örgütsel düzeydir. Karmaşık bir sosyal sistem içerisinde bireyler tarafından birlikte çalışılarak; yeni değerli ürünler (inovasyon), fikirler (ideasyon), hizmetler veya prosedürlerin oluşturulması (problem çözme) ise örgütsel yaratıcılık olarak adlandırılır (Hussain vd., 2017:3). Örgütsel yaratıcılık, yaratıcılık süreçlerinin örgütler içinde uygulanması olarak değerlendirilmektedir (Tuori ve Vilen, 2011:92). Başka bir tanıma göre ise örgütsel yaratıcılık; işgörenlerin içinde var olan potansiyelleri harekete geçirebilme ve yaratıcılık becerisini herkesi kapsayacak şekilde örgütün tamamına yayabilme olarak tanımlanmıştır (Gürüz ve Gürel, 2006:366). Liderler, örgütte var olan yaratıcılık yeteneğini ortaya çıkarır ve bunun için gerekli vizyonu oluştururlar (Cengiz, Acuner ve Baki, 2006:424). Çalışanlarla liderlerin ilişkilerinin pozitif olarak ilerlemesi, liderlerin çalışanların isteklerini cevaplayabilmesi ve çabalarının artması örgütsel yaratıcılık açısından önemlidir (Yılmaz ve Karahan, 2010: 147).

\subsection{Bilgi Paylaşımı}

Bilgi paylaşımı, bilginin örgüt içerisindeki çalışanlar tarafından kullanılabilir hale getirilmesi şeklinde tanımlanabilir (Ipe, 2003:342). Bilgi paylaşımı iki birey veya daha fazla birey arasında bilinçli olarak gerçekleştirilen bir süreçtir. Aynı zamanda bilgi paylaşımı bireyler arasında olabileceği gibi, birey-grup ve gruplar arasında da gerçekleşebilen bir süreçtir (ışık ve Aydın, 2016:78). Liderler, örgütsel bilgi paylaşımını yönetmede hayati bir rol oynamaktadır. Stembert ve Lubart'ın çalışması, bilgi paylaşımının yaratıcılığı desteklediğini belirtmektedir (Stembert ve Lubart, 1999:5). Liderler, göstermiş oldukları davranışlarla örgütsel yaratıcılığın desteklenmesine olanak sağlayan bir örgütsel ortamının oluşturulmasına katkıda bulunarak da çalışanların yaratıcılığını dolaylı yoldan etkilerler. Bu nedenle örgütlerde yaratııılığı artırmak için, yöneticilerin öncelikle yaratıcılıkla ilgili süreci anlamaları, yaratıcı davranışa teşvik etmeleri ve yaratıcılığın gelişebileceği örgüt iklimleri meydana getirmeleri gerekmektedir (Çekmecelioğlu, 2005: 25).

\section{YÖNTEM}

Transaksiyonel liderlik ve transformasyonel liderliğin örgütsel yaratıcılık üzerindeki etkisinde bilgi paylaşımının aracı rolünü belirlemeye yönelik olarak yapılan bu çalışma nedensel bir araştırmadır. Araştırma "transaksiyonel liderlik ve transformasyonel liderliğin örgütsel yaratıcılık üzerindeki etkisinde bilgi paylaşımının aracı rolü var mıdır" sorusuna cevap aramaktadır. Madjar ve arkadaşları (2002), örgüt çalışanlarının yaratıcılıklarının, liderlerinin destekleyici, açık iletişim ve geri besleme (feedback) çabaları nedeniyle olumlu yönde etkilendiğini belirlemiştir (Madjar vd., 2002: 757-767). Çalışanların yaratıcılığının, yöneticilerin onların his ve duygularını anlamaya dönük davranışlarıyla ilişkili olduğu çıkan diğer sonuçlar arasındadır (Oldham, Cummings, 1996: 607-634).

Yazından hareketle araştırmanın ana hipotezleri ve modeli aşağıdaki şekildedir. 
H1: Transaksiyonel liderliğin, bilgi paylaşımı üzerinde anlamlı bir etkisi vardır.

H2: Transaksiyonel liderliğin, örgütsel yaratıcılık üzerinde anlamlı bir etkisi vardır.

H3: Transformasynel liderliğin, bilgi paylaşımı üzerinde anlamlı bir etkisi vardır.

H4: Transformasyonel liderliğin, örgütsel yaratıcılık üzerinde anlamlı bir etkisi vardır.

H5: Bilgi paylaşımının, örgütsel yaratıcılık üzerinde anlamlı bir etkisi vardır.

H6: Transaksiyonel liderliğin, örgütsel yaratıcılık üzerindeki etkisinde bilgi paylaşımının aracı rolü vardır.

H7: Transformasyonel liderliğin, örgütsel yaratıcılık üzerindeki etkisinde bilgi paylaşımının aracı rolü vardır.

Şekil 1: Araştırmanın Modeli

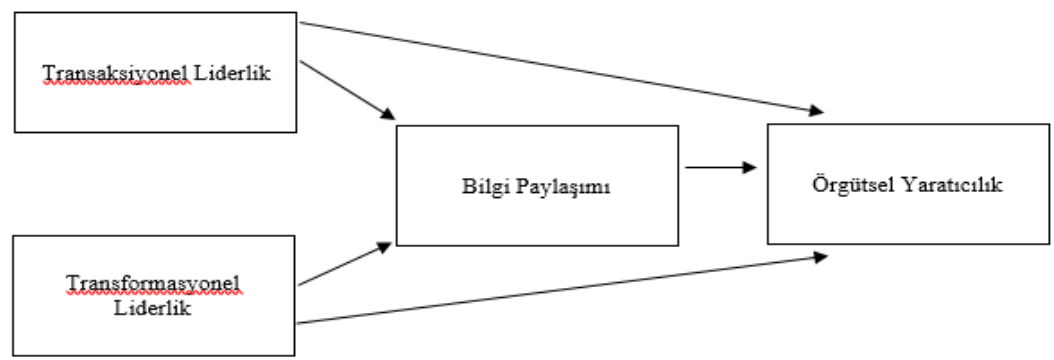

\section{BULGULAR}

\section{1. Ölçeklerin Güvenilirlik ve Geçerlilik Analizleri}

Ölçeklerin yapı geçerliliğinin belirlenebilmesi için varimax rotasyonlu faktör analizinden yararlanılmıştır. Bilgi Paylaşımı ölçeğinin KMO ve Bartlett testi değeri 0.831 ve 0.000 önem ile iki boyuttan (örtülü bilgi paylaşımı, iletişim açıklığı) oluşmaktadır ve toplam varyansın \%65.810'unu açıklanmaktadır. Örgütsel Yaratıcılık ölçeğinin KMO ve Bartlett testi değeri 0.919 ve 0.000 önem ile tek boyutludur ve toplam varyansın \%63.807'sini açıklamaktadır. Transaksiyonel liderlik ölçeğinin KMO ve Bartlett testi değeri 0.797 ve 0.000 önem ile üç boyuttan (koşulsal ödüllendirme, istisnalarla pasif yönetim ve istisnalarla aktif yönetim) oluşmaktadır ve toplam varyansın \%67.597'sini açıklamaktadır. Transformasyonel liderlik ölçeğinin KMO ve Bartlett testi değeri 0.794 ve 0.000 önem ile üç boyuttan (entelektüel uyarım, idealleştirilmiş etki, idealleştirilmiş etki-atfedilen) oluşmaktadır ve toplam varyansın $\% 72.766$ 'sını açıklamaktadır. KMO testi değerinin 0.50 'den büyük olması veri setinin faktör analizi için uygun olduğunu gösterir ve sig. değerinin anlamlı çıkması değişkenler arasındaki korelasyonun anlamlı olduğunu gösterir.

Ölçeklerin güvenilirlik düzeylerinin belirlenebilmesi için yapılan analizler sonucunda Cronbach Alpha katsayısı Bilgi Paylaşımı ölçeği için 0.845, Örgütsel Yaratıcılık ölçeği için 0.935 ve Çoklu Faktör Liderlik Ölçeği için 0.700 olarak bulunmuştur. Bu oranlar Nunnaly'nin belirlediği 0.70 olan kabul edilebilirlik sınııının üzerinde olduğundan dolayı, ölçeklerin güvenilir olduğunu söylemek mümkündür (Altunışık vd., 2005). Faktör analizi sonucunda bilgi paylaşımı ölçeğinde yer alan on üç soru içerisinden faktör yükü $0.05^{\prime}$ in altında ya da eş kökenliğe sahip olan beş soru, çoklu faktör liderlik ölçeğinde yer alan otuz altı soru içerisinden ise on altı soru tespit edilmiş ve analizden çıkarılmıştır.

\section{2. Örnekleme İlişkin Tanımlayıcı İstatistikler ve Korelasyon Değerleri}

Araştırmaya katılan çalışanların \%16’sı 22-25 yaş; \%39,5’i $26-30$ yaş; \%18,5'i 31-35 yaş; \%16’sı 36-40 yaş; \%10'u 41-59 yaş aralığındadır. Katılımcıların \%44,4'ü kadın, \%55,6'sı erkektir. Çalışanların \%60,5'i 0-3 yıl arası, \%26'sının 4-7 yıl arası ve \%13,5'inin 8-9 yıldır mevcut işyerinde çalıştığı görülmektedir.

Tablo 4: Değişkenlere iliş̧kin Tanımlayıcı İstatistikler ve Korelasyon Değerleri

\begin{tabular}{|c|c|c|c|c|c|c|}
\hline Değişkenler & $x$ & SD & 1 & 2 & 3 & 4 \\
\hline 1.Transaksiyonel Liderlik & 3.20 & ,43 & 1 & & & \\
\hline 2.Transformasyonel Liderlik & 3,56 & ,54 &, $304 * *$ & 1 & & \\
\hline 3.Bilgi Paylaşımı & 3,39 & ,75 &, $254 * *$ &, $533 * *$ & 1 & \\
\hline 4.Örgütsel Yaratıcılık & 3,46 &, 82 & ,200* &, $576 * *$ & $739 * *$ & 1 \\
\hline
\end{tabular}

**0,01'e, *0,05'e göre anlamlıdır.

Tablo 4'de değişkenlere ilişkin tanımlayıcı istatistikler ve korelasyon değerlerinin sonuçları yer almaktadır. Değişkenlere ilişkin ortalamalara bakıldığında transformasyonel liderliğin en yüksek değere sahip olduğu görülmektedir. Bilgi paylaşımı ve örgütsel yaratıcılık değerlerine bakıldığında da ortalama bir algıya sahip oldukları dikkat çekmektedir. 
Değişkenlere iliş̧in korelasyon değerlerinin sonuçlarına bakıldı̆ı̆nda ise, örgütsel yaratıılık değişkeni ve bilgi paylaşımı $(, 739)$ değişkeni arasında pozitif yönde yüksek bir illişki olduğu gözlenmektedir. Transformasyonel liderlik değişkeni ile bilgi paylaşımı $(, 533)$ ve örgütsel yaratııılık $(, 576)$ değişkenleri arasında da pozitif yönde orta derecede bir ilişki olduğu ileri sürülebilir.

\subsection{Araştırma Hipotezlerinin Testi}

Tablo 5'de transaksiyonel liderlik ve transformasyonel liderliğin bilgi paylaşımı ve örgütsel yaratıcılık üzerindeki etkisini ve bilgi paylaşımının örgütsel yaratıcılık üzerindeki etkisini ölçmek amacıyla \%95 güven sınırında yapılan regresyon analizi sonuçlarına yer verilmiştir.

Tablo 5: Regresyon Analizi Sonuçları

\begin{tabular}{|c|c|c|c|c|}
\hline Bağımsız Değişken & \multicolumn{4}{|c|}{ Bağımlı Değişkenler } \\
\hline $\begin{array}{l}\text { Transaksiyonel } \\
\text { Liderlik }\end{array}$ & $\begin{array}{l}\text { Bilgi Paylaşımı } \\
\beta \\
0,147 \\
\mathrm{R}^{2}=0,66 \\
\mathrm{~F}=11,078 \\
\end{array}$ & $\begin{array}{l}\text { Sig } \\
0,001\end{array}$ & $\begin{array}{l}\text { Örgütsel Yaratıcılık } \\
\beta \\
0,382 \\
R^{2}=0,040 \\
F=6,680\end{array}$ & $\begin{array}{l}\text { Sig } \\
0,011\end{array}$ \\
\hline $\begin{array}{l}\text { Transformasyonel } \\
\text { Liderlik }\end{array}$ & $\begin{array}{l}\text { Bilgi Paylaşımı } \\
\beta \\
0,732 \\
\mathrm{R}^{2}=0,284 \\
\mathrm{~F}=63,415\end{array}$ & $\begin{array}{l}\text { Sig } \\
0,000\end{array}$ & $\begin{array}{l}\text { Örgütsel Yaratıcılık } \\
\beta \\
0,871 \\
R^{2}=0,331 \\
F=79,309\end{array}$ & $\begin{array}{l}\text { Sig } \\
0,000\end{array}$ \\
\hline Bilgi Paylaşımı & $\begin{array}{l}\text { Örgütsel Yaratıcılık } \\
\beta \\
0,547 \\
\mathrm{R}^{2}=0,814 \\
\mathrm{~F}=193,076\end{array}$ & $\begin{array}{l}\text { Sig } \\
0,000\end{array}$ & & \\
\hline
\end{tabular}

Tablo 5'e göre, model 1'de bilgi paylaşımının \%66'sının transaksiyonel liderliğe bağlı olduğu, Sig. (Anlamlılık) değerinin ( $p=0,001<0,05)$ olması nedeniyle, hesaplanan $\mathrm{R}=0,254$ değerinin ve modelin istatistiksel olarak anlamlı olduğu sonucuna ulaşılmaktadır. Transaksiyonel liderlik ve bilgi paylaşımı değişkenlerine ait regresyon denklemi, (Bilgi Paylaşımı= 2,697+0,147*Transaksiyonel Liderlik) şeklinde yazılır. Bu bağlamda Hipotez 1 kabul edilmiştir ve transaksiyonel liderliğin bilgi paylaşımı üzerinde anlamlı bir etkisi olduğu söylenebilir. Model 2'de örgütsel yaratıcılığın \%4,5'inin transaksiyonel liderliğe bağlı olduğu, Sig. (Anlamlılık) değerinin $(p=0,011<0,05)$ olması nedeniyle, hesaplanan $R=0,200$ değerinin ve modelin istatistiksel olarak anlamlı olduğu sonucuna ulaşılmaktadır. Transaksiyonel liderlik ve örgütsel yaratıcılık değişkenlerine ait regresyon denklemi, (Örgütsel Yaratıcılık= 2,240+0,382*Transaksiyonel Liderlik) şeklinde yazılır. Bu bağlamda Hipotez 2 kabul edilmiştir ve transaksiyonel liderliğin örgütsel yaratıcılık üzerinde anlamlı bir etkisi olduğu söylenebilir. Model 3'de bilgi paylaşımının \%28,4'ünün transformasyonel liderliğe bağlı olduğu, Sig. (Anlamlılı) değerinin $(p=0,000<0,05)$ olması nedeniyle, hesaplanan $R=0,533$ değerinin ve modelin istatistiksel olarak anlamlı olduğu sonucuna ulaşılmaktadır. Transformasyonel liderlik ve bilgi paylaşımı değişkenlerine ait regresyon denklemi, (Bilgi Paylaşımı=0,784+0,732*Transformasyonel Liderlik) şeklinde yazılır. Bu bağlamda Hipotez 3 kabul edilmiştir ve transformasyonel liderliğin bilgi paylaşımı üzerinde anlamlı bir etkisi olduğu söylenebilir. Model 4'de örgütsel yaratıcılığın \%33,1'inin transformasyonel liderliğe bağlı olduğu, Sig. (Anlamlılık) değerinin $(p=0,000<0,05)$ olması nedeniyle, hesaplanan $R=0,576$ değerinin ve modelin istatistiksel olarak anlamlı olduğu sonucuna ulaşılmaktadır. Transformasyonel liderlik ve örgütsel yaratıcılık değişkenlerine ait regresyon denklemi, (Örgütsel Yaratıcılık=0,355+0,871*Transformasyonel Liderlik) şeklinde yazılır. Bu bağlamda Hipotez 4 kabul edilmiştir ve transformasyonel liderliğin örgütsel yaratıcılık üzerinde anlamlı bir etkisi olduğu söylenebilir. Model 5'de örgütsel yaratıcılığın \%54,7'sinin bilgi paylaşımına bağlı olduğu, Sig. (Anlamlılık) değerinin $(p=0,000<0,05)$ olması nedeniyle, hesaplanan $R=0,739$ değerinin ve modelin istatistiksel olarak anlamlı olduğu sonucuna ulaşılmaktadır. Bilgi Paylaşımı ve örgütsel yaratıcılık değişkenlerine ait regresyon denklemi, (Örgütsel Yaratıcılık=0,697+0,814*Bilgi Paylaşımı) şeklinde yazılır. Bu bağlamda Hipotez 5 kabul edilmiştir ve bilgi paylaşımının örgütsel yaratıcılık üzerinde anlamlı bir etkisi olduğu söylenebilir. Buna göre transaksiyonel liderlik ve transformasyonel liderliğin artması durumunda bilgi paylaşımı ve örgütsel yaratıcılığın artacağı, bilgi paylaşımının artması durumunda da örgütsel yaratıcılığın artacağı ifade edilebilir. Bilgi paylaşımı ve örgütsel yaratıcılık üzerinde transformasyonel liderliğin etkisinin, transaksiyonel liderliğin etkisine göre daha fazla olduğu söylenebilir.

Transaksiyonel liderliğin ve transformasyonel liderliğin örgütsel yaratıcılık üzerindeki etkisinde bilgi paylaşımının aracı rolünün belirlenmesinde Baron ve Kenny (1996) tarafından geliştirilen aracı değişken analiz yönteminden yararlanılmıştır. Bu yönteme göre; (1) bağımsız değişkenin aracı değişken üzerinde bir etkisi olmalıdır, (2) bağımsız değişkenin bağımlı değişken üzerinde bir etkisi olmalıdır, (3) aracı değişken ikinci adımdaki regresyon analizine dâhil edildiğinde bağımsız değişkenin bağımlı değişken üzerindeki etkisi azalmalı ya da tamamen ortadan kalkmalıdır. İlk olarak transaksiyonel liderliğin örgütsel yaratıcılık üzerindeki etkisinde bilgi paylaşımının aracı rolü test edilmiştir. Baron ve Kenny'nin birinci ve ikinci koşulları sağlandığından üçüncü koşulun test edilmesi amacıyla transaksiyonel liderlik ve bilgi paylaşımı birlikte analize dâhil edilmiş ve örgütsel yaratıcılık üzerindeki etkilerine bakılmıştır. Buna göre transaksiyonel liderliğin örgütsel yaratıcılık üzerindeki etkisinde Sig. (Anlamlılık) değerinin $(p=0,816>0,05)$ olması nedeniyle, modelin istatistiksel olarak anlamlı olmadığı sonucuna ulaşılmıştır. Bu bağlamda Hipotez 5 red edilmiştir. Transaksiyonel liderliğin örgütsel yaratıcılık üzerindeki etkisinde bilgi paylaşımının aracı rolü yoktur. İkinci olarak transformasyonel liderliğin örgütsel yaratıcılık üzerindeki etkisinde bilgi paylaşımının aracı rolü test edilmiştir. Baron ve Kenny'nin birinci ve ikinci koşulları sağlandığından üçüncü koşulun test edilmesi amacıyla transformasyonel liderlik ve bilgi paylaşımı birlikte analize dâhil edilmiş ve örgütsel yaratıcılık üzerindeki etkilerine bakılmıştır. Regresyon analizi sonuçlarına göre transformasyonel 
liderliğin örgütsel yaratııılık üzerindeki anlamlı etkisi aracı değişken olarak önerilen bilgi paylaşımı analize dâhil edildiğinde azalmıştır $($ [ $=0,384 ; p=0,000<0,05)$. Buna göre transformasyonel liderliğin örgütsel yaratıcılık üzerindeki etkisinde bilgi paylaşımının kısmi aracılık rolünün olduğu sonucuna ulaşılmaktadır. Dolayısıyla Hipotez 6 kabul edilmiştir.

\section{SONUÇ VE ÖNERILER}

Araştırma sonuçlarına göre transaksiyonel liderlik ve transformayonel liderliğin bilgi paylaşımı ve örgütsel yaratıcılık üzerinde anlamlı ve olumlu bir etkisi vardır. Örgütte var olan pozitif çalışma ortamı bilginin örgüt içinde elde edilmesi, kullanılması, paylaşılması ve depolanmasını destekleyen ve etkililiğini arttıran imkânlar sağlamaktadır. Araştırma bulguları alan yazını ile paralellik göstermektedir. Transformasyonel liderliğin örgütsel yaratıcılık üzerinde transaksiyonel liderliğe göre daha fazla etkisi olduğu söylenebilir. Bu çalışmanın yazına en önemli katkısı, sektörel anlamda transaksiyonel ve transformasyonel liderlik ve örgütsel yaratıcılık ilişkisinde bilgi paylaşımının aracılık rolünü inceleyen ilk araştırmalardan biri olmasıdır. Araştırmanın iş dünyası açısından bilişim sektörüne de katkıları bulunmaktadır. Bilişim sektöründe yaratıcılığın ve bilgi paylaşımının önemi oldukça fazladır. Bu nedenle bilgi paylaşımının ve yaratıcılığın önem taşıdığı bilişim sektörü ve diğer sektörlerde bilgi paylaşımının sağlanabilmesi amacıyla liderler tarafından pozitif bir iklim yaratılmalıdır.

Araştırmanın bazı kısıtları bulunmaktadır. Araştırma evreni zaman nedeniyle sadece İstanbul ili ve bilişim sektörü ile sınırlandırılmıştır. Bu konuda çalışma yapmak isteyen araştırmacılar farklı sektörlerde ve illerde araştırmayı tekrarlayabilirler ve ayrıca zehirleyici liderlik, babacan liderlik, stratejik liderlik vb. farklı liderlik çeşitlerinin örgütsel yaratıcılık üzerindeki etkisini inceleyebilirler. Ayrıca bu çalışma Ar\&Ge, reklamcılık vb. bilgi paylaşımının önem taşıdığı farklı sektörlerde yapılabilir. Ayrıca bu araştırma kesitsel bir analiz niteliği taşımaktadır. Farklı zaman dilimlerinde araştırma sonuçları tekrar incelenebilir.

\section{KAYNAKÇA}

Amabile, T. M. (1997). Motivating creativity in organizations: On doing what you love and loving what you do. California Management Review. 40(1): 39-58. DOI: 10.2307/41165921

Aydın, E. (2016). Bilgi Paylaşımının Yenilikçi İş Davranışına Etkisi: Ayder Yaylası Konaklama İşletmeleri Üzerine Bir Araştırma. Girişimcilik ve İnovasyon Yönetimi Dergisi. 5(2): 75-104.

Bakkal, E. Ö. (2018). Hizmet İnovasyonu Uygulamalarında Bilgi Paylaşımı ve İsgören Tatmini: Bir Çağrı Merkezi Örneği. Yayınlanmamış Yüksek Lisans Tezi. İzmir Kâtip Çelebi Üniversitesi Sosyal Bilimler Enstitüsü, İzmir.

Bass, B. (2010). Differences Between The Relationship Of Integrity And Leadership Styles According To The Model Of Bernard Bass. Journal of Management and Economics for Iberoamerica. 26(114): 59-76. DOI: 10.1016/S0123-5923(10)70102-9

Cengiz, E., Acuner, T., \& Baki, B. (2010). Liderlerin Sahip Oldukları Duygusal Zekanın Örgütsel Yaratıcılık Üzerine Etkileri: Bír Model Önerisi. Atatürk Üniversitesi Sosyal Bilimler Enstitüsü Dergisi. 7(1): 421-433.

Çekmecelioğlu, H. (2005). Örgüt İkliminin İş Tatmini Ve İşten Ayrılma Niyeti Üzerindeki Etkisi: Bir Araştırma. C.B.Ü. İktisadi Ve İdari Bilimler Fakültesi Yönetim ve Ekonomi Dergisi. 6(2): 23-39.

Edizler, G., \& Eyyup, A. (2011). Özel Öğretim Kurumlarında Eğitim Yöneticilerinin Dönüşümcü Liderlik Boyutları. Erciyes İletişim Dergisi. 2(2): 20-32.

Gürüz, D., \& Emet, G. (2016). Yönetim ve Organizasyon. Ankara, Nobel Yayınları.

Hussain, S. T., Abbas, J., Lei, S., Jamal Haider, M., \& Akram, T. (2017). Transactional leadership and organizational creativity: Examining the mediating role of knowledge sharing behavior. Cogent Business \& Management. 4(1): 1-11. DOI: 10.1080/23311975.2017.1361663

İpe, M. (2003). Knowledge Sharing in Organizations: A Conceptual Framework. Human Resource Development Review. 2(4): 337-359. DOI: $10.1177 / 1534484303257985$

Kırılmaz, S., \& Harun, K. (2010). Transformasyonel Liderliğin Örgütsel Bağlılık Üzerine Etkileri: Sağlık Bakanlığı Merkez Teşkilatında Bir Araştırma. Türk İdare Dergisi. 469: 119-138.

Madjar, N., Oldham, G. R., \& Pratt, M. G. (2002). There's No Place Like Home: The Contributions Of Work And Nonwork Creativity Support To Employees' Creative Performance. Academy of Management Journal. 45: 757-767. DOI: 10.5465/3069309

Mccal Morgan W., J. (1986). Leadership and Performance Beyond Expectations. Human Resource Management. 25(3): 481. DOI: $10.1002 / \mathrm{hrm} .3930250310$

Northouse, G. P. (2004). Leadership Theory and Practise. Londra, Sage Publications.

Oldham, G.R., \& Cummings A. (1996). Employee Creativity: Personal and Contextual Factors at Work. Academy of Management Journal. 39(3): 607-634. DOI: $10.2307 / 256657$

Sternberg, R. (Ed.). (1998). Handbook of Creativity, Cambridge, Cambridge University Press.

Tuori, A., \& Vilen, T. (2011). Subject Positions and Power Relations in Creative Organizations: Taking a Discursive View on Organizational Creativity. Creativity and Innovation Management. 20(2): 90-99. DOI: 10.1111/j.1467-8691.2011.00596.x

Yılmaz, H., \& Karahan, A., (2010). Liderlik Davranışı, Örgütsel Yaratıcılık ve İşgören Performansı Arasındaki İlişkilerin İncelenmesi: Uşak'ta Bir Araştırma. Yönetim ve Ekonomi. 17(2): 145-158. 